\title{
Endoscopic management of Lynch syndrome and of familial risk of colorectal cancer: European Society of Gastrointestinal Endoscopy (ESGE) Guideline
}

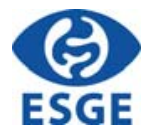

Authors

Monique E. van Leerdam ${ }^{1,2}$, Victorine H. Roos ${ }^{3}$, Jeanin E. van Hooft ${ }^{3}$, Francesc Balaguer ${ }^{4,5}$, Evelien Dekker ${ }^{3}$, Michal F. Kaminski $^{6,7,8}$, Andrew Latchford ${ }^{9,10}$, Helmut Neumann ${ }^{11}$, Luigi Ricciardiello ${ }^{12}$, Maria Rupińska ${ }^{6,7}$, Jean-Christophe Saurin ${ }^{13}$, Pieter J. Tanis ${ }^{14}$, Anja Wagner ${ }^{15}$, Rodrigo Jover ${ }^{16}$, Maria Pellisé ${ }^{4,5}$

Institutions

1 Department of Gastroenterology and Hepatology, Netherlands Cancer Institute, Amsterdam, The Netherlands

2 Department of Gastroenterology and Hepatology, Leiden University Medical Center, Leiden, The Netherlands, Foundation for the Detection of Hereditary Tumours, Leiden, The Netherlands

3 Department of Gastroenterology and Hepatology, Amsterdam University Medical Centers, University of Amsterdam, Cancer Center Amsterdam, Amsterdam, The Netherlands

4 Gastroenterology Department, Hospital Clínic de Barcelona, Barcelona, Spain

5 Centro de Investigación Biomédica en Red de Enfermedades Hepáticas y Digestivas (CIBERehd), Institut d'Investigacions Biomediques August Pi i Sunyer (IDIBAPS), Universitat de Barcelona, Barcelona, Spain

6 Department of Cancer Prevention, The Maria Sklodowska-Curie Memorial Cancer Center and Institute of Oncology, Warsaw, Poland

7 Department of Gastroenterology, Hepatology and Clinical Oncology, Medical Centre for Postgraduate Education, Warsaw, Poland

8 Department of Health Management and Health Economics, University of Oslo, Oslo, Norway

9 Polyposis Registry, St. Mark's Hospital, Harrow, United Kingdom

10 Department of Surgery and Cancer, Imperial College London, London, United Kingdom

11 Department of Medicine I, University Medical Center Mainz, Mainz, Germany

12 Department of Medical and Surgical Sciences, University of Bologna, Bologna, Italy

13 Gastroenterology and Endoscopy Unit, Hospices Civils de Lyon, Hôpital E. Herriot, Lyon, France
14 Department of Surgery, Amsterdam University Medical Centers, University of Amsterdam, Cancer Center Amsterdam, , Amsterdam, The Netherlands

15 Department of Clinical Genetics, Erasmus University Medical Center, Erasmus MC Cancer Institute, Rotterdam, The Netherlands

16 Department of Gastroenterology, Hospital General Universitario de Alicante, Instituto de Investigación Sanitaria y Biomédica de Alicante, ISABIAL, Alicante, Spain

Bibliography

DOI https://doi.org/10.1055/a-1016-4977

Published online: 9.10.2019 | Endoscopy 2019; 51:

1082-1093

(c) Georg Thieme Verlag KG Stuttgart · New York ISSN 0013-726X

\section{Corresponding author}

Monique E. van Leerdam, MD PhD, Department of Gastroenterology and Hepatology, Netherlands Cancer Institute, Plesmanlaan 121, 1066 CX Amsterdam, The Netherlands

Fax: +31-20-5122572

m.v.leerdam@nki.nl

$\bigoplus$ Appendices 1s, 2s

Online content viewable at:

https://doi.org/10.1055/a-1016-4977

\section{MAIN RECOMMENDATIONS}

ESGE recommends that individuals with Lynch syndrome should be followed in dedicated units that practice monitoring of compliance and endoscopic performance measures.

Strong recommendation, low quality evidence, level of agreement $100 \%$. 
ESGE recommends starting colonoscopy surveillance at the age of 25 years for $\mathrm{MLH} 1$ and $M S H 2$ mutation carriers and at the age of 35 years for MSH6 and PMS2 mutation carriers.

Strong recommendation, moderate quality evidence, level of agreement $100 \%$.

ESGE recommends the routine use of high-definition endoscopy systems in individuals with Lynch syndrome.

Strong recommendation, high quality evidence, level of agreement $100 \%$.

ESGE suggests the use of chromoendoscopy may be of benefit in individuals with Lynch syndrome undergoing colonoscopy; however routine use must be balanced against costs, training, and practical considerations.
Weak recommendation, moderate quality evidence, level of agreement $89 \%$.

ESGE recommends definition of familial risk of colorectal cancer as the presence of at least two first-degree relatives with colorectal cancer or at least one first-degree relative with colorectal cancer before the age of 50 years.

Strong recommendation, moderate quality evidence, level of agreement $92 \%$.

ESGE recommends colonoscopy surveillance in first-degree relatives of colorectal cancer patients in families that fulfill the definition of familial risk of colorectal cancer.

Strong recommendation, moderate quality evidence, level of agreement $100 \%$.

\section{SOURCE AND SCOPE}

This Guideline is an official statement of the European Society of Gastrointestinal Endoscopy (ESGE). It provides an overview of the endoscopic management of individuals with Lynch syndrome and individuals with familial risk of colorectal cancer. The Grading of Recommendations Assessment, Development, and Evaluation (GRADE) system was adopted to define the strength of recommendations and the quality of evidence.

\section{Introduction}

Colorectal cancer (CRC) is the fourth most incident cancer and the second leading cause of cancer-related deaths in Europe [1]. While the majority of CRC is sporadic, twin studies have shown that up to $35 \%$ of CRC cases have a familial component [2].

In $2 \%-5 \%$ of CRC cases a genetic origin has been identified [3]. The most common hereditary CRC syndrome is caused by a constitutional pathogenic variant in one of the DNA mismatch repair (MMR) genes (MLH1, MSH2, MSH6, PMS2) or the 3' end of the EpCAM gene; it is also known as Lynch syndrome (LS) and was previously termed hereditary non-polyposis colorectal cancer (HNPCC) [3]. Among CRC cases about 2\%-4\% are caused by LS [4]. As well as increased CRC risk, individuals with LS have a higher risk of developing endometrial, gastric, smallbowel, biliary tract, ovary, urinary tract, brain, and skin cancers. Because of the high cancer risk, it is of great importance that clinicians recognize individuals with LS in order to make appropriate management decisions for both the patient and their atrisk family members. CRC cases associated with polyposis syndromes are discussed in a separate guideline [5].

However, for most cases of CRC with a familial component, no genetic origin is found. The CRC risk in this heterogeneous group of individuals varies. The actual CRC risk depends on the number of family members affected and the age at diagnosis of any affected family member [6], and surveillance should be offered to these individuals based on their estimated CRC risk.
This Guideline provides an overview of the endoscopic management of individuals with LS. Furthermore, we aimed to define familial risk of CRC for those individuals at high risk for CRC to whom, therefore, surveillance should be offered. Since endoscopic management strategies for LS and familial risk of CRC vary widely, we aimed to gain consensus among European experts by using a Delphi process.

\section{Methods}

The ESGE commissioned this Guideline (Guideline Committee chair, J.v.H.) and appointed a Guideline leader (M.v.L), who invited the listed authors to participate in the project development. The key questions were prepared by the coordinating

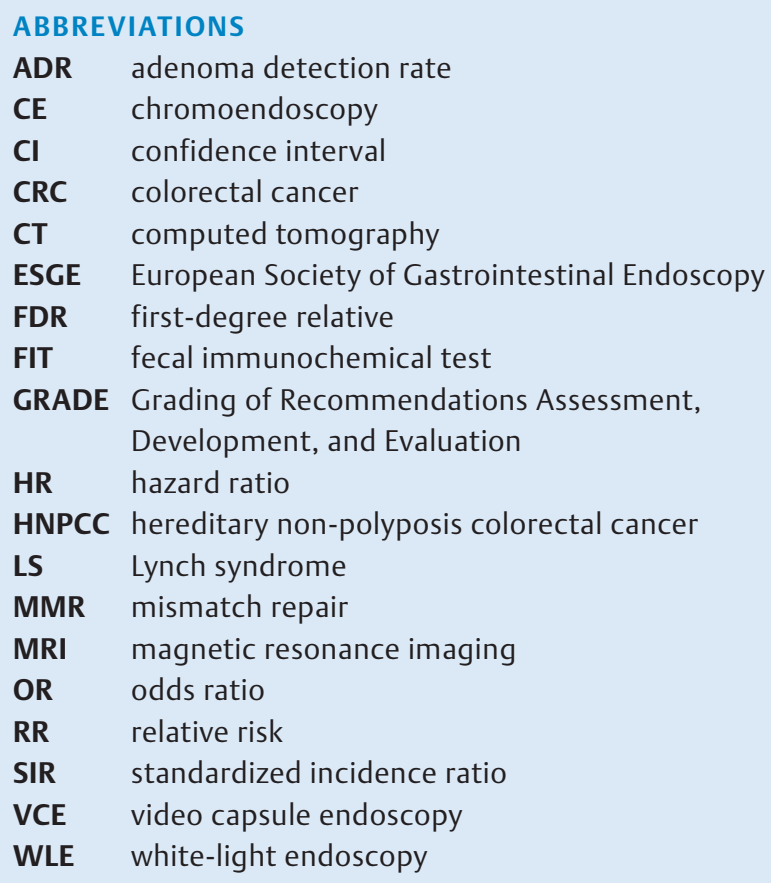


team (M.v.L. and V.R.) and then approved by the other group members. The coordinating team established task force subgroups, each with its own leader and divided the key topics among those task forces (Appendix 1s; see online-only Supplementary Material).

The process of developing the Guideline included telephone conferences, meetings, and online and face-to-face discussions among the members from July 2018 until July 2019. Searches were performed in MEDLINE, Embase, and the Cochrane Library. Articles were selected through title and abstract screening followed by full-text screening. The results of the search were presented to all group members and consensus statements were created.

Evidence levels and recommendation strengths were assessed using the Grading of Recommendations Assessment, Development and Evaluation (GRADE) system [7]. Further details on the methodology of ESGE guidelines have been reported elsewhere [8].

Since literature on familial risk of colorectal cancer and LS is limited, a Delphi process, usually consisting of two rounds, was used in order to obtain consensus [9]. All members, except for the research fellows, were asked to complete the online Delphi questionnaire in isolation, and responses were anonymized to prevent participants from influencing one another [10]. In each round, members were asked to rate all the statements with their level of agreement using a seven-point Likert scale: "Very strongly agree", "Strongly agree”, "Agree”, "Neither agree nor disagree", Disagree", "Strongly disagree”, or "Very strongly disagree" [11]. If the statement was not within their area of expertise, participants could opt out. Secondly, participants were asked whether the statement was clear, and had the opportunity to make suggestions for improvement. After the Delphi round, all statements were discussed and adjusted, if necessary, during a face-to-face meeting. Consensus was reached when $\geq 80 \%$ of the group members had voted either "Very strongly agree", "Strongly agree", or "Agree" during the second Delphi round. Third and fourth Delphi rounds were organized only for the statements regarding advanced imaging.

In July 2019, a draft prepared by M.v.L. and V.R. was sent to all group members. After the agreement of all group members had been obtained, the manuscript was reviewed by a member of the ESGE Governing Board and an external reviewer, and was sent for further comments to the ESGE national societies and individual members. After this, it was submitted to Endoscopy for publication. This Guideline was issued in 2019 and will be considered for update in 2024. Any interim updates will be noted on the ESGE website: http://www.esge.com/esge-guidelines.html.

\section{Lynch syndrome}

\subsection{Background}

This part of the Guideline focuses on individuals with LS, defined as those with a constitutional pathogenic variant in one of the mismatch repair (MMR) genes MLH1, MSH2, MSH6, PMS2, or deletions in the 3' region of the EPCAM gene. The key for identification of LS among CRC cases is testing for MMR deficiency on the tumor tissue, and this is currently the strategy of choice in all individuals diagnosed under the age of 70 years with CRC [12).

It is estimated that at the population level, the prevalence of LS is 1 in 279 (95\% confidence interval [CI] 192 - 493) [13]. Individuals with $L S$ are at risk of early-onset CRC and have a high cumulative lifetime risk of CRC that ranges between $15 \%$ and $70 \%$ at age 70 [14-18]. The adenoma - carcinoma sequence seems to be accelerated, with a reported dwell time as low as 35 months compared with the $10-15$ years in sporadic CRCs [17].

To prevent CRC development or to detect CRC at an early stage, colonoscopy surveillance in LS is essential. Regular colonoscopy surveillance in individuals with LS significantly reduced CRC incidence and associated mortality by more than $50 \%$ [ 18 , 19]. Individuals with LS also have a higher risk of other gastrointestinal malignancies for which endoscopic surveillance may be an option.

\subsection{Colonoscopy surveillance}

\subsubsection{Quality standards}

RECOMMENDATION

ESGE recommends that individuals with Lynch syndrome should be followed in dedicated units that practice monitoring of compliance and endoscopic performance measures.

Strong recommendation, low quality evidence, level of agreement $100 \%$.

Colonoscopy reduces the incidence and mortality of CRC [18-21] in individuals with LS. Post-colonoscopy CRCs are defined by the World Endoscopy Organization as cancers appearing after a colonoscopy in which no cancer is diagnosed, and encompass both interval cancers and non-interval cancers [22]. Interval cancers are those detected before the next recommended surveillance examination. Non-interval cancers are subdivided into cancers detected at (type A) or after (type $B$ ) a recommended surveillance interval or when no subsequent surveillance interval was recommended (type C), up to 10 years following the colonoscopy.

Epidemiological studies have reported that the cumulative CRC rate at 70 years among individuals with LS undergoing colonoscopy surveillance can be as high as $46 \%$ among $M L H 1$, $35 \%$ among MSH2, $20 \%$ among MSH6, and $10 \%$ among PMS2 pathogenic mutation carriers [15]. Some authors postulate that some post-colonoscopy CRCs in LS may emerge from MMR-deficient crypt foci without a polypoid growth pattern and therefore can be difficult to detect by colonoscopy [23]. However, retrospective descriptive studies evaluating postcolonoscopy CRC showed associations with incomplete examination [24-28], inadequate bowel preparation [24-27,29], and possible incomplete resection of lesions [24,30]. Moreover, recommendations on the interval between colonoscopies are not always adhered to and the lack of compliance has been 
reported as another important factor in post-colonoscopy CRC [26-28, 31-38].

Furthermore, high miss rates for colorectal neoplasia (12\%$74 \%$ ) have been reported in several back-to-back colonoscopy studies [39-46]. Therefore, it can be concluded that high quality standards for colonoscopy are not always met in individuals with LS. However, the evidence regarding key performance indicators for colonoscopy in individuals with LS is limited [24-30].

Adherence to the recommended surveillance intervals is important. Some studies have demonstrated that provision of genetic testing [37] and implementation of standardized surveillance programs $[38,47]$ improve compliance. National registries associated with surveillance programs offering regular endoscopic surveillance through the use of reminders show high compliance rates [26-28, $31-36,38]$.

For these reasons, individuals with LS should be followed in dedicated units (national registries, genetic counseling centers, or high-risk cancer centers) where endoscopic surveillance recommendations are monitored in order to improve adherence and to audit the quality of the surveillance program. It should be emphasized that surveillance colonoscopies in individuals with LS should meet the ESGE quality criteria for colonoscopy $[48,49]$.

\subsubsection{Symptomatic LS individuals}

\section{RECOMMENDATION}

ESGE recommends performance of endoscopy earlier than the planned surveillance procedure if an individual with LS is symptomatic.

Strong recommendation, low quality evidence, level of agreement $100 \%$.

This Guideline discusses surveillance intervals for asymptomatic individuals with LS. However, individuals having specific complaints, such as anemia, rectal blood loss, or abdominal pain, should be seen by a gastroenterologist and endoscopies might be indicated at an earlier point in time.

\subsubsection{Colonoscopy surveillance: starting age}

\section{RECOMMENDATION}

ESGE recommends starting colonoscopy surveillance at the age of 25 years for $M L H 1$ and $M S H 2$ mutation carriers and at the age of 35 years for MSH6 and PMS2 mutation carriers.

Strong recommendation, moderate quality evidence, level of agreement $100 \%$.

The appropriate age to start surveillance in order to achieve optimal efficacy has not been established in clinical trials. Thus, the starting age is estimated on the basis of the individual risk of developing advanced adenomas and CRC at a certain age. It has been demonstrated that both the risk of developing earlyonset CRC, as well as the overall CRC risk depend on the MMR gene involved $[14,16,28,50-53]$. In a recent international prospective cohort study including over 3000 unaffected mutation carriers, the cumulative CRC incidence was $46 \%, 43 \%, 15 \%$, and $0 \%$ for carriers of MLH1, MSH2, MSH6, and PMS2 pathogenic variants, respectively, after a mean follow-up time of 7.8 years [16]. Of note, carriers of pathogenic variants of the MSH6 and PMS2 gene had no CRC before 40 years of age. Other studies confirmed that the age of CRC onset in carriers of pathogenic variants of the MSH6 and PMS2 genes was delayed by 10 years compared to carriers of $\mathrm{MLH1}$ and $\mathrm{MSH} 2$ pathogenic variants $[52,53]$, with very low CRC risk before the age of 30 years [51, 52]. Similarly, there was an extremely low risk of developing advanced adenoma (mean number of neoplastic lesions for ages $20-29$ years, $1.3 \pm 0.5$ ) or CRC ( $1 \%$ in 5 years) before the age of 30 for carriers of pathogenic variants of the MLH1 and MSH2 genes [52,53], with very high numbers needed to screen to prevent one CRC death [54]. It is important to take into consideration that, to prevent ascertainment bias, index cases are not included in the retrospective and prospective cohort studies. Mainly among index cases, carriers with a pathogenic MMR variant may present with CRC at a younger age than the proposed starting age for surveillance. However, in view of the cancer risks and the very high numbers needed to screen to detect one lesion at colonoscopy $[17,54]$ it seems justified to defer the start of colonoscopy surveillance to the age of at least 25 years for carriers of pathogenic variants of the $\mathrm{MLH} 1$ and $\mathrm{MSH} 2$ gene and 35 years for carriers of pathogenic variants of the MSH6 and PMS2 genes. A summary of the evidence is provided in Table 1s (Appendix 2, online-only Supplementary Material).

There is no evidence that colonoscopy prior to the age of the youngest CRC diagnosis in the family is beneficial; however it may be advised on an individual basis having fully counseled the individual about the risks and benefits of the procedure.

\subsubsection{Colonoscopy surveillance interval}

\section{RECOMMENDATION}

ESGE recommends a high quality surveillance colonoscopy every 2 years in asymptomatic individuals with Lynch syndrome.

Strong recommendation, moderate quality evidence, level of agreement $90 \%$.

\section{RECOMMENDATION}

ESGE recommends to repeat complete colonoscopy within 3 months in the case of a colonoscopy of suboptimal quality (poor bowel preparation or incomplete procedure).

Strong recommendation, moderate quality evidence, level of agreement $90 \%$.

Randomized controlled trials for surveillance in LS mutation carriers are unavailable; therefore we have to rely on retrospective or prospective observational studies that indirectly 
compare rates of post-colonoscopy CRC and their stage distribution with different surveillance intervals. A summary of these studies is provided in Table 2s. Post-colonoscopy CRCs were observed irrespective of the 1-, 2-, or 3-year colonoscopy surveillance interval used in each of the published studies [14-17, 28, 50 -55]. In a recent large international study involving 2747 carriers of pathogenic variants of the MLH1, MSH2, or MSH6 genes, reporting on over 16000 colonoscopies, no differences in post-colonoscopy CRC rates or CRC stage distribution were observed among three different surveillance policies used, in LS registries from Germany (1-year interval), the Netherlands (1-2-year interval), and Finland (2-3-year interval) [35]. Furthermore, in multiple studies the average time from the date of colonoscopy to CRC diagnosis was between 24 and 36 months, which may support intervals longer than 1 year [31, $32,56]$. Of note, overall survival rates in patients diagnosed with post-colonoscopy CRC within surveillance programs were excellent and exceeded $90 \%[24,27,32,36,56,57]$.

As the data on colonoscopy quality in the studies comparing different surveillance intervals were limited, as were the data on compliance to assigned surveillance intervals and the evidence for a stratified approach for the different constitutional pathogenic variants in the MMR genes, it seems justified to propose a uniform 2-year interval irrespective of the pathogenic variant.

The evidence for the increased risk for metachronous CRC in individuals with LS after polyp removal or CRC resection is not unequivocal $[31,32,35,58]$. In a study from the Netherlands neither the presence of an adenoma, nor its characteristics were associated with an increased risk for CRC [32]. However, Engel et al. showed that a prevalent adenoma at index colonoscopy was actually associated with a higher cumulative CRC incidence [35]. Besides, it was suggested that incomplete removal of an adenoma might be a significant contributor to the risk of post-colonoscopy CRC [24]. In other studies the risk of developing a metachronous adenoma or CRC after surgery for CRC (segmental or subtotal colectomy) was relatively low, providing that surveillance was performed within 2 years [27, 58]. Awaiting further evidence, shortening surveillance intervals to less than 2 years should only be considered in special situations. Currently, limited data support a longer surveillance interval for carriers of a pathogenic variant of MSH6 and PMS2, who do carry a lower cumulative CRC incidence. It has been suggested that PMS2-associated CRCs do have a distinct tumor biology, which may support a longer surveillance interval for PMS2 carriers if the data are confirmed [59].

A high quality examination is considered to be one of the key factors for optimal effectiveness of surveillance colonoscopy, and therefore, surveillance colonoscopies in individuals with LS should meet the ESGE quality criteria for colonoscopy [24, 48, 49] (see also above). Perrod et al. evaluated a surveillance program that assigned surveillance intervals based on the quality of the previous colonoscopy (cleanness, completeness, and use of chromoendoscopy), and demonstrated an improvement in quality, a reduction in post-colonoscopy CRC, and increased detection of flat dysplasia [60]. So when suboptimal bowel preparation (Boston Bowel Preparation Scale $<2$ in one of the colon segments) is found or the procedure is incomplete, colo- noscopy should be repeated within 3 months before entering the 2-year surveillance period.

\subsubsection{Colonoscopy surveillance: advanced imaging techniques}

\section{RECOMMENDATION}

ESGE recommends the routine use of high-definition endoscopy systems in individuals with Lynch syndrome. Strong recommendation, high quality evidence, level of agreement $100 \%$.

\section{RECOMMENDATION}

ESGE suggests the use of chromoendoscopy may be of benefit in individuals with Lynch syndrome undergoing colonoscopy; however routine use must be balanced against costs, training, and practical considerations.

Weak recommendation, moderate quality evidence, level of agreement $89 \%$.

In the literature, seven studies compared indigo carmine chromoendoscopy with white-light endoscopy (WLE) in individuals with LS (Table 3As) [39-41,44, 45].

Three small single-center studies with a back-to-back design and standard-definition endoscopes demonstrated that chromoendoscopy was superior to WLE, reporting a WLE adenoma miss rate ranging from $61 \%$ to $74 \%[39,40,45]$. Very recently another back-to-back multicenter study, in which the second pass was performed by a different gastroenterologist, again demonstrated superiority of standard-definition chromoendoscopy over standard-definition WLE, reporting an adenoma miss rate of $52 \%$ [41]. However, all these studies are methodologically flawed as the back-to-back design entails that the second pass is always done with chromoendoscopy, which may have led to an overestimation of the effect of chromoendoscopy over WLE.

Three parallel trials with a control arm are available $[44,61$, 62]. A small back-to-back study with two arms, namely WLE followed by either intensive inspection of over 20 minutes or WLEchromoendoscopy, showed no significant difference in adenoma miss rate between the two strategies [44]. Recently, two large multicenter randomized parallel trials did not demonstrate benefit for chromoendoscopy compared to WLE [61,62]. A Dutch study in 246 individuals with constitutional pathogenic variants in one of the MMR genes showed no difference in neoplasia detection rate between chromoendoscopy and WLE, both at baseline colonoscopy $(27 \%$ versus $30 \%$, respectively, $P=$ 0.56 ), and at the 2-year follow-up colonoscopy (26\% versus $28 \%$ respectively, $P=0.81$ ) [61]. A multicenter non-inferiority Spanish study in 256 carriers with a constitutional pathogenic variant in one of the MMR genes showed similarly high adenoma detection rates (ADRs), for high-definition WLE and chromoendoscopy (ADR 28.1\%, $95 \% \mathrm{Cl} 21.1 \%-36.4 \%$ versus $34.4 \%$, $95 \% \mathrm{Cl} 26.4 \%-43.3 \%$, respectively; $P=0.28$ ) [62]. However, 
there was a non-statistically significant trend regarding the detection rate of flat adenomas in favor of pancolonic chromoendoscopy $(24.2 \%$, 95\% Cl $17.1 \%-32.6 \%)$ compared with WLE (14.8\%, $95 \% \mathrm{Cl} 9.2 \%-22.2 \%)(P=0.06)$. Of note, only high-level detector endoscopists were involved in both studies, and in the second one all the endoscopes were high-definition.

Virtual chromoendoscopy was superior to WLE in two backto-back studies in individuals with LS (Table 3Bs) [42,43]. On the other hand, virtual chromoendoscopy was inferior to dyebased chromoendoscopy in two back-to-back studies [40,63]. Thus, at present the role of virtual chromoendoscopy in the surveillance of individuals with LS is not yet well established.

Comment: Utility of chromoendoscopy In the past 10 years, detection rates for colorectal lesions have gradually increased, because of improvements in endoscopic technology as well as the implementation of quality indicators in screening colonoscopy. The incremental effect of chromoendoscopy over WLE for detecting adenomas in LS may have been overestimated because of the methodological limitations in most previous studies. In fact, in back-to-back studies WLE ADRs ranged from $9 \%$ to $23 \%$ and in the two recent parallel studies WLE ADRs ranged from $26 \%$ to $28 \%$. This might imply that a thorough inspection by high-level detector endoscopists and the use of high-definition endoscopes might outweigh the advantageous effect of chromoendoscopy. Nevertheless, for low-level detector endoscopists or when high definition is not available, the use of chromoendoscopy still remains advisable.

\subsection{Gastric surveillance}

\section{RECOMMENDATION}

ESGE does not recommend routine gastric surveillance in individuals with Lynch syndrome.

Strong recommendation, low quality evidence, level of agreement $100 \%$.

\section{RECOMMENDATION}

ESGE suggests (non-invasive) testing for Helicobacter pylori in individuals with Lynch syndrome.

Weak recommendation, moderate quality evidence, level of agreement $90 \%$.

Individuals with LS have a cumulative lifetime risk ranging from $0.7 \%$ to $13 \%$ of developing gastric cancer [64]. Data show a trend towards an increased prevalence of gastric cancer for carriers of pathogenic variants of the MLH1 or MSH2 genes compared with carriers of a pathogenic variant of the MSH6 gene [64]. Most of the gastric cancers were diagnosed in individuals older than 45 years, with reported median ages ranging from 55 to 64 years (overall ranges 27 - 85) [65-68]. Among all individuals with LS who developed gastric cancer, $0-31 \%$ had a family history of gastric cancer [65-68].
There are no RCTs evaluating the effect of gastric surveillance in individuals with LS, but three observational studies have been published [68-70] (Table 4s). In two retrospective observational cohort studies about $30 \%$ of the individuals with LS had undergone an esophagogastroduodenoscopy $[68,69]$. In a Turkish study, $19.1 \%$ of the mutation carriers had $H$. pylori gastritis, atrophic gastritis, or gastrointestinal metaplasia [69]. A positive family history was not significantly associated with having abnormal esophagogastroduodenoscopy findings [69]. In a Dutch study, esophagogastroduodenoscopy revealed gastric cancer in 8 individuals $(6.1 \%)$, biopsies confirmed inflammation in 23 (17.4\%), intestinal metaplasia in 4 (3.0\%), and no pathological or endoscopic abnormalities in 97 (73.5\%) [68]. Of these individuals with LS, $20 \%$ were $H$. pylori-positive [68]. In a non-randomized comparative Finnish study, a single esophagogastroduodenoscopy was performed both in carriers of a pathogenic variant in the MLH1 gene (median age 49 years) and in mutation-negative family members (median age 51 years) [70]. In individuals with a pathogenic variant of the MLH1 gene, $H$. pylori infection was observed in $26 \%$, atrophy in $14 \%$, and intestinal metaplasia in $14 \%$; these findings were similar to those in the control group [70]. So in view of the apparently limited gastric cancer risk in individuals with LS and lack of evidence regarding benefit of gastric surveillance, such surveillance is not routinely recommended.

A meta-analysis including 7 randomized controlled trials in the general population showed that $H$. pylori eradication reduces gastric cancer incidence by $35 \%$ [71]. Furthermore, population screening for $H$. pylori has been found to be cost-effective [72]. Although no direct evidence is present, one could assume that individuals with LS would also benefit from $H$. pylori screening and eradication.

\subsection{Small-bowel surveillance}

\section{RECOMMENDATION}

ESGE does not recommend routine small-bowel surveillance in individuals with Lynch syndrome.

Strong recommendation, moderate quality evidence, level of agreement $100 \%$.

In individuals with LS, the cumulative risk of developing small-bowel cancer before the age of 70 years ranged from $0.6 \%(95 \% \mathrm{Cl} 0.1 \%-1.3 \%)$ to $7.2 \%(95 \% \mathrm{Cl} 1.5 \%-12.9 \%)$ in carriers of a pathogenic variant of the MLH1 gene [64]. There is a 100 -fold increase in the risk of developing small-bowel cancer in individuals having LS compared with the general population [73]. The incidence of small-bowel cancer in individuals with LS was highest among carriers of pathogenic variants of the $M L H 1$ or MSH2 genes and most often seen in males (57\% - 79\%) [7476]. The median age of diagnosis varied from 39 to 53 years [77-83]. The majority of the small-bowel cancers were located in the duodenum or jejunum [77-82] and histology showed adenocarcinoma in $81 \%$ to $100 \%$ of the cases [ 79,81$]$.

Two studies have investigated the use of video capsule endoscopy (VCE) in asymptomatic carriers of a pathogenic vari- 
ant and observed small-bowel neoplasia prevalences of $1.5 \%$ and $8.6 \%$ [84, 85] (Table 5s). In a Dutch study including 200 individuals with LS, one patient was diagnosed with a T2N0Mx duodenal cancer 7 months after a negative VCE [84]. The other study, among 35 individuals with LS, reported no small-bowel cancers after a mean follow-up of 40 months [85]. Furthermore, $70 \%$ of individuals had a false-positive finding, resulting in unnecessary invasive secondary procedures such as balloonenteroscopy or magnetic resonance imaging (MRI) enteroclysis [84]. The second study compared VCE with computed tomography $(C T)$ enteroclysis and showed that $C T$ enteroclysis missed two of the three cases of small-bowel neoplasia [85]. Another study demonstrated that repeat VCE after a mean interval of 2.2 years in $78 \%$ of the asymptomatic individuals with LS resulted in no detection of small-bowel neoplasia [86].

In a recent French prospective study among 154 individuals with LS, that evaluated the yield of esophagogastroduodenoscopy performed every $3-4$ years on the occasion of a colonoscopy, a total of 3 duodenal adenocarcinoma cases and 4 duodenal adenoma cases were found [87]. Of the 7 individuals with duodenal neoplasia, 3 were carriers of a pathogenic variant in the $\mathrm{MSH} 2$ gene.

Currently, the reported prevalence of small-bowel neoplasia among asymptomatic individuals with LS is low and the benefit of small-bowel surveillance is not clear; routine surveillance of the small bowel is not recommended. A large prospective study is necessary to determine the value of surveillance esophagogastroduodenoscopy for both the gastric and duodenal cancer risk in individuals with LS.

\section{Familial risk of colorectal cancer}

\subsection{Definition}

In about $20 \%-30 \%$ of individuals diagnosed with CRC, a familial history of CRC is reported [3]. The CRC risk in individuals with a family history of CRC depends on the number of affected family members and the age of diagnosis of CRC in the family. According to various guidelines, individuals with a family history of CRC should undergo more intensive surveillance strategies than the general population, starting at an earlier age [8890]. However, definitions of who should undergo more intensive surveillance show wide geographic variation.

\section{RECOMMENDATION}

ESGE recommends definition of familial risk of colorectal cancer as the presence of at least two first-degree relatives with colorectal cancer or at least one first-degree relative with colorectal cancer before the age of 50 years. Strong recommendation, moderate quality evidence, level of agreement $92 \%$.

Five meta-analyses have evaluated the influence of family history on relative and absolute risk of CRC [91-95]. In a recently published systematic review and meta-analysis, Wong et al. found that individuals having at least one first-degree relative (FDR) with CRC had a lower increased risk of developing CRC (relative risk [RR] 1.76, 95\%Cl 1.57-1.97; $P<0.001$ ) [91] than previously reported risk estimates (RRs ranging from 2.24 to 2.26) [92-94]. This lower estimate of the risk of developing CRC among FDRs was confirmed by a recent meta-analysis that grouped risk estimates by study design; it reported a pooled RR among cohort studies of $1.67(95 \% \mathrm{Cl} 1.52-1.82)$ and a pooled RR among case-control studies of $2.22(95 \% \mathrm{Cl} 2.00-2.48)$ in the presence of at least one FDR with CRC (Table 6s) [95]. A higher pooled RR was found in the presence of two or more FDRs, with pooled RRs of CRC of 2.40 (cohort) and 2.81 (casecontrol) [95]. When CRC was diagnosed before the age of 50 years in an FDR, the pooled RRs were $3.26(95 \% \mathrm{Cl} 2.82-3.77$; cohort) and 3.57 (95\%Cl $1.07-11.85$; case-control) [95]. Since cohort studies are less likely to contain recall bias, the authors considered the summary estimates of cohort studies to be closer to the truth. These RRs corresponded to a cumulative absolute risk for CRC, at 85 years in Western Europe, of $4.8 \%(95 \% \mathrm{Cl}$ $2.7 \%-8.3 \%$ ) for those with one affected FDR, increasing to 8.2 $\%(95 \% \mathrm{Cl} 6.1 \%-10.9 \%)$ for those with two or more affected FDRs, and of $11 \%(95 \% \mathrm{Cl} 9.5 \%-12.4 \%)$ when there was an affected FDR below the age of 50 years at diagnosis [95]. Individuals having at least one second-degree relative with CRC showed no clinically significant increased risk of developing CRC with a pooled RR among cohort studies of $1.09(95 \% \mathrm{Cl}$ $1.03-1.15)$.

Previously published guidelines have reported that familial risk of CRC should be defined as having a relevantly increased risk of developing $C R C$, often set at two to three times the general population risk $[89,96,97]$. Therefore ESGE proposes to define familial risk of CRC as being present in those having two or more FDRs with CRC or one FDR with CRC below the age of 50 years.

\subsection{Surveillance in familial risk of CRC}

\subsubsection{Protective effect}

\section{RECOMMENDATION}

ESGE recommends colonoscopy surveillance in firstdegree relatives of CRC cases in families that fulfill the definition of familial risk of colorectal cancer. Strong recommendation, moderate quality evidence, level of agreement $100 \%$.

Only two studies have addressed the protective effect of colonoscopy in individuals with at least one FDR with CRC $[98,99]$ (Table 7s). Dove-Edwin et al. registered the outcomes of screening colonoscopy in a clinic for high-risk families during 16 years, with the aim of determining to what extent individuals with various family histories of CRC (specified in Table 7s) benefit from colonoscopic surveillance [98]. Among 1678 individuals, the observed number of CRC cases was lower than the expected number of cases in the absence of surveillance, with a reduction in CRC incidence of $80 \%$ and a reduction of CRC mor- 
tality of $81 \%$. However, this study has several limitations such as the lack of a robust control group as well as the possibility of underreporting of CRC cases since the study relied on UK National Health Service (NHS) registry data. In the second study, Hatfield et al. described the findings of screening colonoscopy in a cohort of 20 families and 332 individuals with type $X$ familial risk of CRC (families fulfilling the Amsterdam criteria, but with MMR-proficient tumors), including 162 individuals receiving colonoscopy surveillance and 162 not receiving surveillance. In this study they found that surveillance colonoscopy reduced both CRC incidence (men, RR 0.27 [95\%Cl $0.10-0.71$ ]; women, RR 0.19 [95\%Cl $0.07-0.48]$ ) and CRC-related mortality (men, RR 0.38 [95\% Cl 0.15-0.94]; women, RR 0.19 [95\%Cl $0.07-0.49]$ ) [99]. This study also had several limitations such as the non-randomized allocation of the intervention, historical controls, retrospective data collection, and incomplete medical records.

In summary, in individuals with a significant family history of CRC, colonoscopy surveillance seems to reduce CRC incidence and mortality; however, more studies are needed in order to know to what extent.

\subsubsection{Surveillance intervals}

\section{RECOMMENDATION}

ESGE recommends a 5-year surveillance interval for colonoscopy after a normal high quality baseline examination in the setting of familial risk of colorectal cancer.

Strong recommendation, low quality evidence, level of agreement $83 \%$.

\section{RECOMMENDATION}

ESGE recommends that follow-up after polyp excision in individuals with familial risk of colorectal cancer should follow the surveillance guidelines for the general population.

Strong recommendation, moderate quality evidence, level of agreement $92 \%$.

Previous guidelines recommend an interval between colonoscopies of 5 years in those with a family history of CRC [88, 89]. Different studies have analyzed the risk of developing CRC or advanced neoplasia after a negative colonoscopy among individuals with at least one FDR with CRC (excluding individuals with LS). The vast majority of these studies do not show any increase in risk of metachronous neoplasia after colonoscopy (Table 7s).

In a population-based case-control study, Brenner et al. showed that the risk of developing CRC is low up to 20 years after a negative colonoscopy [100]. The odds ratio (OR) for developing CRC for individuals with at least one FDR with CRC was $0.66(95 \% \mathrm{Cl} 0.27-1.58)$ within $5-9$ years after a negative colonoscopy and $0.47(95 \% \mathrm{Cl} 0.14-1.59)$ more than 10 years after a negative colonoscopy. The protective effect in individ- uals without a family history was higher, with an OR of 0.23 $(95 \% \mathrm{Cl} 0.15-0.36)$ within $5-9$ years and $0.33(95 \% \mathrm{Cl} 0.23-$ 0.48 ) for more than 10 years after a negative colonoscopy. Furthermore, Samadder et al. performed an observational cohort study including 131349 individuals and found that, compared with the general population of Utah, the standardized incidence ratio (SIR) for CRC was consistently low until 10 years after a negative colonoscopy, but in individuals with at least one FDR with CRC this risk reduction only extends until 5 years after a negative colonoscopy [101]. In the latter group a first negative colonoscopy was associated with a statistically significant reduced incidence of CRC for only the first 5 years (SIR $0.39,95 \% \mathrm{Cl} 0.13-0.64)$; after this 5-year interval, the negative colonoscopy was no longer protective for CRC (SIR 0.74, $95 \% \mathrm{CI}$ $0.32-1.16)$. However, this study has some limitations, with the very small numbers of observed CRC cases after 5 years limiting the statistical power of the results.

Surveillance after polyp excision According to the studies evaluating the yield of colonoscopy after adenoma removal, there is no evidence that supports shortening the surveillance interval in individuals with a family history of CRC (Table 7s). There is only one randomized controlled trial comparing different colonoscopy intervals (6 versus 3 years) in people with a family history of CRC [102]. In this study that included 528 individuals (with one affected FDR aged $<50$ years or two affected FDRs) with $0-2$ adenomas at baseline, Hennink et al. found no significant difference in the proportion of individuals with advanced adenomas at the first follow-up examination at 6 years $(6.9 \%)$ versus 3 years (3.5\%), with a crude OR of 2.0 ( $\mathrm{Cl} 0.9-$ 4.7). The authors concluded that, in view of the relatively low rate of advanced adenomas at 6 years and the very low risk of CRC (only one CRC was detected in the 3-year arm), a 6-year surveillance interval should be considered as appropriate.

Based on the limited evidence, a 5-year surveillance interval is advised after a negative colonoscopy for individuals with familial risk of CRC. Furthermore, surveillance guidelines for average-risk populations after adenoma removal can be followed.

\subsubsection{Starting age for colonoscopy surveillance}

\section{RECOMMENDATION}

ESGE recommends starting colonoscopy surveillance at the age of 40 years when there is a familial risk of colorectal cancer.

Strong recommendation, moderate quality evidence, level of agreement $92 \%$.

The majority of guidelines recommend starting colonoscopy screening in individuals with a family history of CRC (mostly defined as an affected FDR aged less than 60 years or two affected FDRs) at 40 years of age or 10 years earlier than the age of the youngest index case $[88,89]$. The rationale for age 40 years initially comes from the study of Fuchs et al. [103] (Table 8s). In this study, for 40-year-old individuals with a family history of CRC, the cumulative incidence of CRC was comparable to that 
of 50-year-old individuals without a family history. Hemminki \& $\mathrm{Li}$ in a large prospective cohort study found similar results, reporting an SIR of $2.01(95 \% \mathrm{Cl} 1.71-2.33)$ for individuals aged $40-49$ years at diagnosis, with at least one affected FDR with CRC, compared with an SIR of 1.18 (95\%CI 0.99-1.39) for individuals over 50 years at diagnosis [104]. Other studies found an increase of CRC incidence and mortality at an age younger than 50 years in relatives of CRC patients [105-107]. CRC incidence was increased with an RR of 2.07 (95\% Cl $0.99-$ 3.80) for relatives aged 50 years and less [105]. The CRC standardized mortality ratio ranged between $12.5(95 \% \mathrm{Cl} 1.52$ $45.14)$ and $3.66(95 \% \mathrm{Cl} 1.47-7.55)$ in individuals between 35 and 55 years [106]. Additionally, a case-control study found that individuals younger than 50 years had a significantly higher relative risk of CRC compared to those older than 50 years of age ( $R R<50$ years 8.54 [ $95 \% C l 1.9-39]$ vs. $R R \geq 50$ years 1.87 [95\%Cl 1.4-2.8]) [107]. This is confirmed by another casecontrol study including 18208 CRC patients from a cancer registry that did find an increased risk for FDR at younger ages (< 50 years), and although FDRs in both age groups ( $<50$ and $>50$ years) were consistently at increased cancer risk, FDRs of young-onset $C R C$ cases ( $<40$ years old) had the highest familial risk when they were younger than 50 years of age (HR 7.0 [95\% $\mathrm{Cl} 2.86$ - 17.09]) [108].

There is no evidence that colonoscopy 10 or 5 years prior to the youngest CRC diagnosis in the family is beneficial; however it may be advised on an individual basis having fully counseled an individual about the risks and benefits of the procedure.

Based on these results, we do advise to start colonoscopy surveillance at the age of 40 years for individuals with familial risk of colorectal cancer.

On the other hand, all these results come from observational studies and are based on relative risk estimates. In a recent systematic review and meta-analysis, the absolute risk estimates for CRC at different ages were calculated [95]. The results showed that the risk of CRC is less than $1 \%$ in the next 10 years for 40-year-old individuals fulfilling the criteria for familial risk of CRC, and moves to close to $2 \%$ in the next 10 years for these individuals at 50 years. In the near future when more evidence is available, these results may support starting surveillance for individuals with familial risk of CRC at 50 years.

\section{Comments}

This Guideline provides a framework for the endoscopic management of individuals with LS, and proposes a definition of familial risk of colorectal cancer to identify the group of individuals in whom colonoscopy surveillance is justified, as they have a high risk ( RR > 2.5) for developing CRC.

Evidence is limited in several areas and further research is needed. Such areas include, among others: evaluation of the optimal starting ages and intervals for colonoscopy surveillance among individuals with LS and those with familial risk of CRC; the yield of stomach and small-bowel surveillance in LS; and the yield of fecal immunochemical test (FIT) screening among individuals at familial risk of CRC.

\section{Disclaimer}

The legal disclaimer for ESGE guidelines [8] applies to this Guideline.

\section{Acknowledgments}

The authors gratefully thank Prof. C. Hassan, of the Nuovo Regina Margherita Hospital, Rome, and Dr. C. Engel, of the Institute for Medical Informatics, Statistics and Epidemiology, Leipzig, for their valuable comments on the manuscript.

Furthermore, we would like to thank Ariadna Sanchez, Liseth Rivero-Sánchez, Sabela Carballal, Carolina Mangas-Sanjuan, Gerhard Jung, Aleksandar Gavric, Dr. Dora Colussi, Dr. Chiara Pierantoni, and Faridi van Etten-Jamaludin for their assistance regarding the systematic searches and literature review.

Lastly, we would like to thank Claire Guy for arranging the Delphi procedure and Pauline Rocheteau and Francoise Heidenreich for organizing all the meetings and telephone conferences for the Guideline.

\section{Competing interests}

E. Dekker was an advisory board chair for Cancer Prevention Pharmaceuticals (2019) and is a Co-Editor for Endoscopy. M.F. Kaminski has received speaker's, teaching, and consultancy fees from Olympus (2017 to present) and speaker's and teaching fees, and a loan of equipment from Fujifilm (2019). H. Neuman has provided consultancy services to Fujifilm and Pentax (2012 to present). M. Pellisé has received consultancy fees from Norgine Iberia (2019), speaker's fees from Casen Recordati (2017-2019), Olympus (2017), and Jansen (2018), and is a Co-Editor for Endoscopy; her department has received an equipment loan from Fujifilm (2017 to present) and a research donation from Fujifilm (2019). J.E. van Hooft has received lecture fees from Medtronics (2014 - 2015) and Cook Medical (2019), and consultancy fees from Boston Scientific (2014-2017); her department has received research grants from Cook Medical (2014-2018) and Abbott (2014-2017). F. Balaguer, R. Jover, A. Latchford, L. Ricciardiello, V.H. Roos, M. Rupińska, J.-C. Saurin, P.J. Tanis, M. E. van Leerdam, and A. Wagner have no competing interests.

\section{References}

[1] Bray F, Ferlay ], Soerjomataram I et al. Global cancer statistics 2018: GLOBOCAN estimates of incidence and mortality worldwide for 36 cancers in 185 countries. CA Cancer J Clin 2018; 68: 394-424

[2] Lichtenstein P, Holm NV, Verkasalo PK et al. Environmental and heritable factors in the causation of cancer - analyses of cohorts of twins from Sweden, Denmark, and Finland. N Engl J Med 2000; 343 : 78-85

[3] Jasperson KW, Tuohy TM, Neklason DW et al. Hereditary and familial colon cancer. Gastroenterology 2010; 138: 2044-2058

[4] Hampel H, Frankel WL, Martin E et al. Feasibility of screening for Lynch syndrome among patients with colorectal cancer. J Clin Oncol 2008; 26: 5783-5788

[5] van Leerdam ME, Roos VH, van Hooft JE et al. Endoscopic management of polyposis syndromes: European Society of Gastrointestinal Endoscopy (ESGE) Guideline. Endoscopy 2019; 51: 877-895

[6] Armelao F, de Pretis G. Familial colorectal cancer: a review. World J Gastroenterol 2014; 20: 9292-9298 
[7] Atkins D, Best D, Briss PA et al. Grading quality of evidence and strength of recommendations. BMJ 2004; 328: 1490

[8] Dumonceau JM, Hassan C, Riphaus A et al. European Society of Gastrointestinal Endoscopy (ESGE) guideline development policy. Endoscopy 2012; 44: 626-629

[9] Linstone HA, Turoff M. The Delphi method: Techniques and applications. Addison-Wesley Educational Publishers Inc; 1975

[10] Jones J, Hunter D. Consensus methods for medical and health services research. BMJ 1995; 311: 376-380

[11] Likert R. A technique for the measurement of attitudes. Arch Psychol 1932; 22: 5-55

[12] Moreira L, Balaguer $\mathrm{F}$, Lindor $\mathrm{N}$ et al. Identification of Lynch syndrome among patients with colorectal cancer. JAMA 2012; 308: 1555-1565

[13] Win AK, Jenkins MA, Dowty JG et al. Prevalence and penetrance of major genes and polygenes for colorectal cancer. Cancer Epidemiol Biomarkers Prev 2017; 26: 404-412

[14] Ramsoekh D, Wagner A, van Leerdam ME et al. Cancer risk in MLH1, MSH2 and MSH6 mutation carriers; different risk profiles may influence clinical management. Hered Cancer Clin Pract 2009; 7: 17

[15] Moller P, Seppala T, Bernstein I et al. Cancer incidence and survival in Lynch syndrome patients receiving colonoscopic and gynaecological surveillance: first report from the prospective Lynch syndrome database. Gut 2017; 66: 464-472

[16] Moller P, Seppala TT, Bernstein I et al. Cancer risk and survival in path_MMR carriers by gene and gender up to 75 years of age: a report from the Prospective Lynch Syndrome Database. Gut 2018; 67: 1306-1316

[17] Edelstein DL, Axilbund J, Baxter M et al. Rapid development of colorectal neoplasia in patients with Lynch syndrome. Clin Gastroenterol Hepatol 2011; 9: 340-343

[18] Jarvinen HJ, Aarnio M, Mustonen $\mathrm{H}$ et al. Controlled 15-year trial on screening for colorectal cancer in families with hereditary nonpolyposis colorectal cancer. Gastroenterology 2000; 118: 829-834

[19] de Jong AE, Hendriks YM, Kleibeuker JH et al. Decrease in mortality in Lynch syndrome families because of surveillance. Gastroenterology 2006; 130: 665-671

[20] Jarvinen HJ, Mecklin JP, Sistonen P. Screening reduces colorectal cancer rate in families with hereditary nonpolyposis colorectal cancer. Gastroenterology 1995; 108: 1405-1411

[21] Barrow P, Khan M, Lalloo F et al. Systematic review of the impact of registration and screening on colorectal cancer incidence and mortality in familial adenomatous polyposis and Lynch syndrome. $\mathrm{Br}$ Surg 2013; 100: 1719-1731

[22] Rutter MD, Beintaris I, Valori R et al. World Endoscopy Organization consensus statements on post-colonoscopy and post-imaging colorectal cancer. Gastroenterology 2018; 155: 909-925.e3

[23] Ahadova A, von Knebel DoeberitzM, Blaker $\mathrm{H}$ et al. CTNNB1-mutant colorectal carcinomas with immediate invasive growth: a model of interval cancers in Lynch syndrome. Fam Cancer 2016; 15: 579-586

[24] Haanstra JF, Vasen HF, Sanduleanu S et al. Quality colonoscopy and risk of interval cancer in Lynch syndrome. Int J Colorectal Dis 2013; 28: $1643-1649$

[25] Vale Rodrigues R, Claro I, Lage P et al. Colorectal cancer surveillance in Portuguese families with lynch syndrome: a cohort study. Int ] Colorectal Dis 2018; 33: 695-702

[26] Newton K, Green K, Lalloo F et al. Colonoscopy screening compliance and outcomes in patients with Lynch syndrome. Colorectal Dis 2015; 17 : 38-46

[27] de Vos tot Nederveen Cappel WH, Nagengast FM, Griffioen G et al. Surveillance for hereditary nonpolyposis colorectal cancer: a longterm study on 114 families. Dis Colon Rectum 2002; 45: 1588-1594
[28] Vasen HF, Abdirahman M, Brohet R et al. One to 2-year surveillance intervals reduce risk of colorectal cancer in families with Lynch syndrome. Gastroenterology 2010; 138: 2300-2306

[29] van Vugt van Pinxteren MW, van Kouwen MC, van Oijen MG et al. A prospective study of bowel preparation for colonoscopy with polyethylene glycol-electrolyte solution versus sodium phosphate in Lynch syndrome: a randomized trial. Fam Cancer 2012; 11: 337-341

[30] Argillander TE, Koornstra J], van Kouwen M et al. Features of incident colorectal cancer in Lynch syndrome. United European Gastroenterol J 2018; 6: 1215-1222

[31] Anyla M, Lefevre JH, Creavin B et al. Metachronous colorectal cancer risk in Lynch syndrome patients-should the endoscopic surveillance be more intensive? Int J Colorectal Dis 2018; 33: 703-708

[32] de Jong AE, Nagengast FM, Kleibeuker JH et al. What is the appropriate screening protocol in Lynch syndrome? Fam Cancer 2006; 5: 373-378

[33] Jarvinen H], Renkonen-Sinisalo L, Aktan-Collan K et al. Ten years after mutation testing for Lynch syndrome: cancer incidence and outcome in mutation-positive and mutation-negative family members. J Clin Oncol 2009; 27: 4793-4797

[34] Engel C, Rahner N, Schulmann K et al. Efficacy of annual colonoscopic surveillance in individuals with hereditary nonpolyposis colorectal cancer. Clin Gastroenterol Hepatol 2010; 8: 174-182

[35] Engel C, Vasen HF, Seppala T et al. No difference in colorectal cancer incidence or stage at detection by colonoscopy among 3 countries with different Lynch syndrome surveillance policies. Gastroenterology 2018; 155: 1400-1409.e2

[36] Stuckless S, Green JS, Morgenstern M et al. Impact of colonoscopic screening in male and female Lynch syndrome carriers with an MSH2 mutation. Clin Genet 2012; 82: 439-445

[37] Stoffel EM, Mercado RC, Kohlmann W et al. Prevalence and predictors of appropriate colorectal cancer surveillance in Lynch syndrome. American J Gastroenterol 2010; 105: 1851-1860

[38] Sjostrom O, Lindholm L, Tavelin B et al. Decentralized colonoscopic surveillance with high patient compliance prevents hereditary and familial colorectal cancer. Fam Cancer 2016; 15: 543-551

[39] Lecomte T, Cellier C, Meatchi T et al. Chromoendoscopic colonoscopy for detecting preneoplastic lesions in hereditary nonpolyposis colorectal cancer syndrome. Clin Gastroenterol Hepatol 2005; 3: 897-902

[40] Huneburg R, Lammert F, Rabe C et al. Chromocolonoscopy detects more adenomas than white light colonoscopy or narrow band imaging colonoscopy in hereditary nonpolyposis colorectal cancer screening. Endoscopy 2009; 41: 316-322

[41] Rahmi G, Lecomte T, Malka D et al. Impact of chromoscopy on adenoma detection in patients with Lynch syndrome: a prospective, multicenter, blinded, tandem colonoscopy study. American J Gastroenterol 2015; 110: 288-298

[42] Bisschops R, Tejpar S, Willekens $\mathrm{H}$ et al. Virtual chromoendoscopy (I-SCAN) detects more polyps in patients with Lynch syndrome: a randomized controlled crossover trial. Endoscopy 2017; 49: 342350

[43] East JE, Suzuki N, Stavrinidis M et al. Narrow band imaging for colonoscopic surveillance in hereditary non-polyposis colorectal cancer. Gut 2008; 57: 65-70

[44] Stoffel EM, Turgeon DK, Stockwell DH et al. Missed adenomas during colonoscopic surveillance in individuals with Lynch Syndrome (hereditary nonpolyposis colorectal cancer). Cancer Prev Res (Phila) 2008; 1: 470-475

[45] Hurlstone DP, Karajeh M, Cross SS et al. The role of high-magnification-chromoscopic colonoscopy in hereditary nonpolyposis colorectal cancer screening: a prospective "back-to-back" endoscopic study. American J Gastroenterol 2005; 100: 2167-2173 
[46] Ramsoekh D, Haringsma J, Poley JW et al. A back-to-back comparison of white light video endoscopy with autofluorescence endoscopy for adenoma detection in high-risk subjects. Gut 2010; 59: 785-793

[47] Schneider JL, Goddard KAB, Muessig KR et al. Patient and provider perspectives on adherence to and care coordination of lynch syndrome surveillance recommendations: findings from qualitative interviews. Hered Cancer Clin Pract 2018; 16: 11

[48] Kaminski MF, Thomas-Gibson S, Bugajski M et al. Performance measures for lower gastrointestinal endoscopy: a European Society of Gastrointestinal Endoscopy (ESGE) Quality Improvement Initiative. Endoscopy 2017; 49: 378-397

[49] Kaminski MF, Hassan C, Bisschops R et al. Advanced imaging for detection and differentiation of colorectal neoplasia: European Society of Gastrointestinal Endoscopy (ESGE) Guideline. Endoscopy 2014; 46: 435-449

[50] Ten Broeke SW, van der Klift HM, Tops CM] et al. Cancer risks for PMS2-associated Lynch syndrome. J Clin Oncol 2018; 36: 2961-2968

[51] Hendriks YM, Wagner A, Morreau $\mathrm{H}$ et al. Cancer risk in hereditary nonpolyposis colorectal cancer due to MSH6 mutations: impact on counseling and surveillance. Gastroenterology 2004; 127: 17-25

[52] Plaschke J, Engel C, Kruger S et al. Lower incidence of colorectal cancer and later age of disease onset in 27 families with pathogenic MSH6 germline mutations compared with families with MLH1 or MSH2 mutations: the German Hereditary Nonpolyposis Colorectal Cancer Consortium. J Clin Oncol 2004; 22: 4486-4494

[53] Sanchez A, Navarro M, Ocaña T et al. Colorectal cancer incidence in Lynch syndrome patients: first report of a multicenter nation-wide study. Gastroenterology 2017; 152: S552

[54] Jenkins MA, Dowty JG, Ait OuakrimD et al. Short-term risk of colorectal cancer in individuals with lynch syndrome: a meta-analysis. J Clin Oncol 2015; 33: 326-331

[55] Lamba M, Ebel R, Hamilton SM et al. 828 - What's my risk of cancer doctor? Interval colorectal cancer risk in Lynch syndrome: Results from the New Zealand National Registry Gastroenterology 2019; 156: $\mathrm{S}-179$

[56] Seppala T, Pylvanainen K, Evans DG et al. Colorectal cancer incidence in path_MLH1 carriers subjected to different follow-up protocols: a prospective Lynch syndrome database report. Hered Cancer Clin Pract 2017; 15: 18

[57] Stupart DA, Goldberg PA, Algar U et al. Surveillance colonoscopy improves survival in a cohort of subjects with a single mismatch repair gene mutation. Colorectal Dis 2009; 11: 126-130

[58] Lee G, Lee W, Park Y et al. The surveillance of colorectal adenoma and carcinoma after colectomy for hereditary nonpolyposis colorectal cancer in a positive DNA mismatch repair gene mutation test. Dis Colon Rectum 2012; 55: e213

[59] Ten Broeke SW, van Bavel TC, Jansen AML et al. Molecular background of colorectal tumors from patients with Lynch syndrome associated with germline variants in PMS2. Gastroenterology 2018 155: 844-851

[60] Perrod G, Samaha E, Rahmi G et al. Impact of an optimized colonoscopic screening program for patients with Lynch syndrome: 6-year results of a specialized French network. Therap Adv Gastroenterol 2018; 11: 1756284818775058

[61] Haanstra JF, Dekker E, Cats A et al. Effect of chromoendoscopy in the proximal colon on colorectal neoplasia detection in Lynch syndrome: a multicenter randomized controlled trial. Gastrointest Endosc 2019: doi:10.1016/j.gie.2019.04.227 [Epub ahead of print]

[62] Rivero-Sánchez L, Arnau-Collell C, Herrero J et al. White-light endoscopy is adequate for Lynch syndrome surveillance in a randomized and non-inferiority study. Gastroenterology 2019: doi:10.1053/j.gastro.2019.09.003 [Epub ahead of print]
[63] Samaha E, Bellanger J, Dhooge M et al. Sa1900 Comparison of colonoscopy with virtual chromoendoscopy using third generation narrow band imaging system to chromoendoscopy with indigo carmine in Lynch syndrome patients (the lynch-chromo study). Gastrointest Endosc 2018; 87: AB241

[64] Barrow E, Hill J, Gareth Evans D. Cancer risk in Lynch syndrome. Fam Cancer12: 229-240

[65] Fornasarig M, Magris R, De Re V et al. Molecular and pathological features of gastric cancer in Lynch Syndrome and familial adenomatous polyposis. Int J Mol Sci 2018: doi:10.3390/ijms19061682

[66] Capelle LG, Van Grieken NC, Lingsma HF et al. Risk and epidemiological time trends of gastric cancer in Lynch syndrome carriers in the Netherlands. Gastroenterology 2010; 138: 487-492

[67] Aarnio M, Salovaara R, Aaltonen LA et al. Features of gastric cancer in hereditary non-polyposis colorectal cancer syndrome. Int J Cancer 1997; 74: 551-555

[68] Soer EC, Leicher LW, Langers AM et al. Equivalent Helicobacter pylori infection rates in Lynch syndrome mutation carriers with and without a first-degree relative with gastric cancer. Int J Colorectal Dis 2016; 31: 693-697

[69] Galiatsatos P, Labos C, Jeanjean M et al. Low yield of gastroscopy in patients with Lynch syndrome. Turk J Gastroenterol 2017; 28: 434438

[70] Renkonen-Sinisalo L, Sipponen P, Aarnio M et al. No support for endoscopic surveillance for gastric cancer in hereditary non-polyposis colorectal cancer. Scand J Gastroenterol 2002; 37: 574-547

[71] Fuccio L, Zagari RM, Minardi ME et al. Systematic review: Helicobacter pylori eradication for the prevention of gastric cancer. Aliment Pharmacol Ther 2007; 25: 133-141

[72] Lansdorp-Vogelaar I, Sharp L. Cost-effectiveness of screening and treating Helicobacter pylori for gastric cancer prevention. Best Pract Res Clin Gastroenterol 2013; 27: 933-947

[73] Koornstra JJ, Kleibeuker JH, Vasen HF. Small-bowel cancer in Lynch syndrome: is it time for surveillance? Lancet Oncol 2008; 9: 901-905

[74] Barrow E, Robinson L, Alduaij W et al. Cumulative lifetime incidence of extracolonic cancers in Lynch syndrome: a report of 121 families with proven mutations. Clin Genet 2009; 75: 141-149

[75] Bonadona V, Bonaiti B, Olschwang S et al. Cancer risks associated with germline mutations in MLH1, MSH2, and MSH6 genes in Lynch syndrome. JAMA 2011; 305: 2304-2310

[76] Vasen HF, Stormorken A, Menko FH et al. MSH2 mutation carriers are at higher risk of cancer than MLH1 mutation carriers: a study of hereditary nonpolyposis colorectal cancer families. J Clin Oncol 2001; 19: $4074-4080$

[77] Lynch HT, Smyrk TC, Lynch PM et al. Adenocarcinoma of the small bowel in lynch syndrome II. Cancer 1989; 64: 2178-2183

[78] Parc Y, Boisson C, Thomas G et al. Cancer risk in 348 French MSH2 or MLH1 gene carriers. J Med Genet 2003; 40: 208-213

[79] Park JG, Kim DW, Hong CW et al. Germ line mutations of mismatch repair genes in hereditary nonpolyposis colorectal cancer patients with small bowel cancer: International Society for Gastrointestinal Hereditary Tumours Collaborative Study. Clinical Cancer Res 2006; 12: 3389-3393

[80] Rodriguez-Bigas MA, Vasen HF, Lynch HT et al. Characteristics of small bowel carcinoma in hereditary nonpolyposis colorectal carcinoma. International Collaborative Group on HNPCC. Cancer 1998; 83: $240-244$

[81] Schulmann K, Brasch FE, Kunstmann E et al. HNPCC-associated small bowel cancer: clinical and molecular characteristics. Gastroenterology 2005; 128: 590-599

[82] ten Kate GL, Kleibeuker JH, Nagengast FM et al. Is surveillance of the small bowel indicated for Lynch syndrome families? Gut 2007; 56: 1198-1201 
[83] Watson P, Lynch HT. Extracolonic cancer in hereditary nonpolyposis colorectal cancer. Cancer 1993; 71: 677-685

[84] Haanstra JF, Al-Toma A, Dekker E et al. Prevalence of small-bowel neoplasia in Lynch syndrome assessed by video capsule endoscopy. Gut 2015; 64: 1578-1583

[85] Saurin JC, Pilleul F, Soussan EB et al. Small-bowel capsule endoscopy diagnoses early and advanced neoplasms in asymptomatic patients with Lynch syndrome. Endoscopy 2010; 42: 1057-1062

[86] Haanstra JF, Al-Toma A, Dekker $E$ et al. Incidence of small bowel neoplasia in Lynch syndrome assessed by video capsule endoscopy. Endosc Int Open 2017; 5: E622-E626

[87] Hammoudi N, Dhooge M, Coriat R et al. Duodenal tumor risk in Lynch syndrome. Dig Liver Dis 2019; 51: 299-303

[88] Rex DK, Boland CR, Dominitz JA et al. Colorectal cancer screening: recommendations for physicians and patients from the U.S. MultiSociety Task Force on Colorectal Cancer. Gastroenterology 2017; 153: 307-323

[89] Leddin D, Lieberman DA, Tse F et al. Clinical practice guideline on screening for colorectal cancer in individuals with a family history of nonhereditary colorectal cancer or adenoma: The Canadian Association of Gastroenterology Banff Consensus. Gastroenterology 2018; 155: 1325-1347.e3

[90] Provenzale D, Jasperson K, Ahnen D] et al. Colorectal cancer screening, version 1.2015. J Natl Compr Canc Netw 2015; 13: 959-968; quiz 68

[91] Wong MCS, Chan CH, Lin J et al. Lower relative contribution of positive family history to colorectal cancer risk with increasing age: a systematic review and meta-analysis of 9.28 million individuals. American J Gastroenterol 2018; 113: 1819-1827

[92] Butterworth AS, Higgins JP, Pharoah P. Relative and absolute risk of colorectal cancer for individuals with a family history: a meta-analysis. Eur J Cancer 2006; 42: 216-227

[93] Baglietto L, Jenkins MA, Severi G et al. Measures of familial aggregation depend on definition of family history: meta-analysis for colorectal cancer. J Clin Epidemiol 2006; 59: 114-124

[94] Johns LE, Houlston RS. A systematic review and meta-analysis of familial colorectal cancer risk. American J Gastroenterol 2001; 96: 2992-3003

[95] Roos VH, Mangas-Sanjuan C, Rodriguez-Girondo M et al. Influence of family history on relative and absolute colorectal cancer risk: a systematic review and meta-analysis. Clin Gastroenterol Hepatol 2019: Sep 13. pii: S1542-3565(19)30995-4. doi:10.1016/j. cgh.2019.09.007 [Epub ahead of print]
[96] Burt RW. Colon cancer screening. Gastroenterology 2000; 119 : 837-853

[97] Kerber RA, Neklason DW, Samowitz WS et al. Frequency of familial colon cancer and hereditary nonpolyposis colorectal cancer (Lynch syndrome) in a large population database. Fam Cancer 2005; 4: 239-244

[98] Dove-Edwin I, Sasieni P, Adams J et al. Prevention of colorectal cancer by colonoscopic surveillance in individuals with a family history of colorectal cancer: 16 year, prospective, follow-up study. BM] 2005; 331: 1047

[99] Hatfield E, Green JS, Woods MO et al. Impact of colonoscopic screening in familial colorectal cancer type X. Mol Genet Genomic Med 2018; 6: 1021-1030

[100] Brenner $\mathrm{H}$, Chang-Claude J, Seiler CM et al. Long-term risk of colorectal cancer after negative colonoscopy. J Clin Oncol 2011; 29: 3761-3767

[101] Samadder NJ, Pappas L, Boucherr KM et al. Long-term colorectal cancer incidence after negative colonoscopy in the state of Utah: the effect of family history. Am J Gastroenterol 2017; 112: 1439-1447

[102] Hennink SD, van der Meulen-de Jong AE, Wolterbeek R et al. Randomized comparison of surveillance intervals in familial colorectal cancer. J Clin Oncol 2015; 33: 4188-4193

[103] Fuchs CS, Giovannucci EL, Colditz GA et al. A prospective study of family history and the risk of colorectal cancer. N Engl J Med 1994: 331: 1669-1674

[104] Hemminki K, Li X. Familial colorectal adenocarcinoma from the Swedish Family-Cancer Database. Int J Cancer 2001; 94: 743-748

[105] Andrieu N, Launoy G, Guillois R et al. Familial relative risk of colorectal cancer: a population-based study. Eur J Cancer 2003; 39: 19041911

[106] Johns LE, Kee F, Collins B] et al. Colorectal cancer mortality in firstdegree relatives of early-onset colorectal cancer cases. Dis Colon Rectum 2002; 45: 681-686

[107] Kune GA, Kune S, Watson LF. The role of heredity in the etiology of large bowel cancer: data from the Melbourne Colorectal Cancer Study. World J Surg 1989; 13: 124-129; discussion 9-31

[108] Samadder NJ, Smith KR, Hanson $\mathrm{H}$ et al. Increased risk of colorectal cancer among family members of all ages, regardless of age of index case at diagnosis. Clin Gastroenterol Hepatol 2015; 13: 2305-2311. e1-2 